\title{
A estrutura curricular dos cursos de Odontologia no Brasil
}

\author{
A organização curricular dos cursos passa por transformações \\ importantes no momento atual, que resultam, de certa forma, da \\ exigência das novas Diretrizes Curriculares para a área de Saúde.
}

\author{
Lilian Marly de Paula*, Ana Cristina Barreto Bezerra**
}

* Doutora em Ciências da Saúde, Departamento de Odontologia,

Faculdade de Ciências da Saúde, Universidade de Brasília.

** Pós-Doutora pela Faculdade de Odontologia de Michigan.

\section{RESUMO}

O ensino formal de Odontologia no Brasil, que teve seu início no final do século XIX, evoluiu significativamente ao longo do tempo, no entanto, manteve sua prática centrada na formação técnica. Este trabalho avalia, fundamentalmente a partir dos currículos disponibilizados pelo banco de dados do Instituto Nacional de Pesquisas Educacionais Anísio Teixeira - Ministério da Educação (INEP/MEC), a participação das áreas: de formação básica, profissionalizante, ética e cidadania, saúde coletiva, e de novas áreas do conhecimento na totalidade da carga horária dos cursos. Desse modo, possibilita observar a importância dada a cada área na organização geral dos cursos de Odontologia no País.

\section{DESCRITORES}

Ensino. Educação em Odontologia. Currículo.

o ensino superior brasileiro inspirado no modelo acadêmico francês prima, desde o seu início, pela formação de profissionais para o mercado de trabalho. As atividades de pesquisar, produzir e socializar conhecimentos, consonantes com a função da Universidade, ficam, em um país com escassez de recursos para a educação, limitadas à capacidade de obtenção de financiamento. Vale ressaltar que, em sua maioria, estas atividades estão concentradas nas Universidades públicas, excluídas algumas privadas geralmente de ordem confessional (MASETTO, 1998).

O Censo de Educação Superior 2002, divulgado em outubro de 2003, claramente demonstra que o crescimento do ensino superior foi sustentado pelo ensino privado (INEP/MEC, 2003). Em decorrência da natureza destas instituições e da conjuntura econômica do país, a produção científica de novos conhecimentos permanece restrita aos centros capazes de captar recursos, o que reforça o modelo inicial de formação técnica para o mercado de trabalho.

A Odontologia, regulamentada em 1856 como profissão, foi exercida a título de concessão. Baseada no empirismo, era uma prática eminentemente artesanal. Os primeiros cursos, criados no Rio de Janeiro e na Bahia, apresentavam duração de dois a três anos. O currículo da época era constituído por matérias básicas: Anatomia da Cabeça, Histologia Dentária, Fisiologia Dentária, Patologia Dentária, Física e Química Mineral Elementar, e matérias profissionais: Terapêutica Dentária, Medicina Operatória e Cirurgia Dentária (FERNANDES NETO, 2002). Somente em 1951, foi estabelecido que o seu exercício era exclusivo dos habilitados por título obtido em escola de Odontologia (CARVAlHo, 2001). Nos últimos 50 anos a influência norte-americana se fez marcante e o curso foi objeto de transformações mediante a agregação de novos conhecimentos e tecnologias até chegar ao modelo de ensino hoje observado, estabelecido pela Lei de Diretrizes e Bases de 1996 e pelas Diretrizes Curriculares de fevereiro de 2002.

Notadamente nos últimos 10 anos, ocorreu uma grande expansão na quantidade de cursos de Odontologia no Brasil com o conseqüente aumento do número de profissionais que ingressam no 
Tabela 1 - Distribuição regional dos cursos de Odontologia em relação à população brasileira por região.

\begin{tabular}{|l|c|r|r|}
\hline $\begin{array}{c}\text { Regiáo do } \\
\text { Brasil }\end{array}$ & $\begin{array}{c}\text { Quantidade } \\
\text { de cursos }\end{array}$ & $\begin{array}{c}\text { Quantidade } \\
\text { de vagas }\end{array}$ & População \\
\hline Norte & 12 & $792^{*}$ & 12.900 .704 \\
\hline Nordeste & 25 & 1.787 & 47.741 .711 \\
\hline Sudeste & 92 & $7.488^{\star *}$ & 72.412 .411 \\
\hline Centro-Oeste & 11 & 840 & 11.636 .728 \\
\hline Sul & 30 & $2.205^{\star \star *}$ & 25.107 .616 \\
\hline Brasil & 170 & 13.112 & 169.799 .170 \\
\hline
\end{tabular}

Fonte: INEP/MEC 2003; IBGE 2000.

* exceto quantidade de vagas de um curso de Rondônia.

** exceto quantidade de vagas de dois cursos no Rio de Janeiro, três em São Paulo e um em Minas Gerais.

***exceto quantidade de vagas de dois cursos no Paraná.

mercado de trabalho. Na Tabela 1, pode ser observada a grande concentração de cursos e de vagas nas regiões sudeste e sul do país, nesta exclusivamente do ponto de vista proporcional - os dados referentes à quantidade de cursos e de vagas foram coletados no cadastro das instituições de ensino superior do MEC em outubro de 2003.

Proceder a uma discussão da estrutura curricular dos cursos de Odontologia exige, prioritariamente, o estabelecimento de uma conceituação do termo currículo que oriente o caminhar para o objetivo estabelecido. Neste contexto, o currículo constitui a programação norteadora da formação acadêmica, executada mediante o processo educacional inerente à aplicação de conteúdos e práticas, com a meta primordial de preparar técnica, científica, moral, ética, social e intelectualmente os futuros profissionais das diferentes áreas do conhecimento.

Cabe considerar, ainda, que a organização curricular dos cursos passa por transformações importantes no momento atual, que resultam, de certa forma, de exigência oficial, originada das novas Diretrizes Curriculares para área de saúde, incluída a Odontologia.

O perfil profissional estabelecido pelas diretrizes curriculares requer

\footnotetext{
"formação profissional generalista, humanista, crítica e reflexiva, para atuar em todos os níveis de atenção à saúde, com base no rigor técnico e científico. Capacitado ao exercício de atividades referentes à saúde bucal da população, pautado em princípios éticos, legais e na compreensão da realidade social, cultural e econômica do seu meio, dirigindo a atuação para a transformação da
}

realidade em benefício da sociedade" (Resolução CNE/CES 3/2002).

São fixadas, também, nas diretrizes curriculares, as competências e as habilidades gerais e específicas que devem advir da formação profissional do cirurgião-dentista.

As habilidades gerais exigem: atenção à saúde, tomada de decisões, comunicação, liderança, administração e gerenciamento, além de educação permanente.

Por sua vez, entre as capacidades específicas que devem resultar da formação estão aquelas necessárias para colher, observar e interpretar dados para a construção do diagnóstico; identificar as afecções bucomaxilofaciais prevalentes; desenvolver o raciocínio lógico e a análise crítica na conduta clínica; propor e executar planos de tratamento adequados; realizar a promoção e manutenção da saúde; comunicar-se com pacientes, com profissionais de sa úde e com a comunidade em geral, dentro de preceitos éticos e legais; trabalhar em equipes interdisciplinares e atuar como agente de promoção de saúde; planejar e administrar serviços de saúde coletiva; acompanhar e incorporar inovações tecnológicas (informática, novos materiais, biotecnologia) no exercício da profissão (Resolução CNE/CES 3/2002: Diretrizes Curriculares).

Substancialmente, as diretrizes requerem currículo que prepare um profissional com formação ética e científica, possuidor de visão integral da saúde nos âmbitos coletivo e individual, capaz de lidar com problemas simples ou complexos e, que, quando for o caso, detenha conhecimentos avançados em biotecnologia, informática e novos materiais e tecnologias.

Enquanto isso, a prática odontológica está vislumbrando modificações devido aos avanços no campo da Biologia (HART, 2000; YEAGER, 2001; SLAVKIN, 1996 e 2000). Atualmente, está em curso uma transformação da etiopatogenia das doenças que afetam o sistema estomatognático, induzindo o desenvolvimento de novas abordagens terapêuticas que buscam integrar conhecimentos da Terapia Gênica, da Engenharia de Tecidos e da Biotecnologia (BAUM et al., 2002). Esses fatos trouxeram ao meio acadêmico a discussão a respeito do desafio que enfrentam os cursos de Odontologia da atualidade: continuar formando profissionais para a prática clínica atual e, concomitantemente, oferecer-lhes ferramentas para o enfrentamento de prática radicalmente diversa no futuro (BERTOLAMI, 
Tabela 2 - Distribuição dos cursos da amostra segundo a dependência administrativa.

\begin{tabular}{|c|c|c|c|c|}
\hline \multirow{2}{*}{$\begin{array}{c}\text { Número } \\
\text { de cursos }\end{array}$} & \multicolumn{4}{|c|}{ Dependência administrativa } \\
\cline { 2 - 5 } & Federal & Estadual & Municipal & Particular \\
\hline 89 & 21 & 7 & 2 & 59 \\
\hline
\end{tabular}

2001).

Neste contexto, o presente trabalho tem como proposta a realização de análise da situação curricular dos cursos de Odontologia no Brasil.

\section{Objetivo geral}

Estudar a estrutura curricular dos cursos de Odontologia no Brasil.

\section{Objetivos específicos}

1. Caracterizar a estrutura curricular dos cursos de Odontologia.

2. Determinar a média e a correlação de horas das áreas: de formação básica, profissionalizante, ética e cidadania, saúde coletiva, formação científica e de novas áreas do conhecimento em relação à carga horária total dos currículos dos cursos de Odontologia. 3. Verificar a compatibilidade da estrutura curricular com as novas diretrizes curriculares do MEC.

\section{MATERIAL E MÉTODOS}

A coleta de dados foi baseada em:

1. banco de dados do INEP/MEC 2002;

2. solicitação direta às instituições;

3. sítios institucionais na Internet.

As informações foram extraídas das grades curriculares vigentes em 2002 e classificadas de acordo com os critérios abaixo listados:

1. área básica: Anatomia, Histologia, Fisiologia, Embriologia, Genética, Bioquímica, Microbiologia, Imunologia, Farmacologia e Patologia;

2. área profissionalizante: Materiais Dentários, Semiologia, Estomatologia, Anestesiologia, Oclusão, Fisiologia Dentária, Dentística, Endodontia, Periodontia, Cirurgia, Odontopediatria, Prótese, Clínica Integrada e todas as clínicas e estágios profissionalizantes;

3. área ética e cidadania: Filosofia, Sociologia, Antropologia, Psicologia, Educação Religiosa, Português, Língua Estrangeira, Prática Esportiva, Odontologia Legal e Orientação Profissional;

4. área saúde coletiva: Odontologia Social, Preventiva, Saúde Pública, Epidemiologia, Estágios Comunitários, Programas de Saúde;

5. área formação científica: Metodologia Científica, Estatística, Bioestatística, Informática, Trabalho
Tabela 3 - Quantidade de cursos da amostra por estado.

\begin{tabular}{|l|c|l|c|}
\hline \multicolumn{1}{|c|}{ Estado } & $\begin{array}{c}\text { № de } \\
\text { cursos }\end{array}$ & \multicolumn{1}{|c|}{ Estado } & $\begin{array}{c}\text { № de } \\
\text { cursos }\end{array}$ \\
\hline Alagoas & 1 & Pará & 2 \\
\hline Amazonas & 2 & Paraíba & 1 \\
\hline Ceará & 2 & Paraná & 6 \\
\hline Bahia & 2 & Pernambuco & 1 \\
\hline Distrito Federal & 4 & Piauí & 1 \\
\hline Espírito Santo & 1 & $\begin{array}{l}\text { Rio Grande } \\
\text { do Norte }\end{array}$ & 1 \\
\hline Goiás & 2 & $\begin{array}{l}\text { Rio Grande } \\
\text { do Sul }\end{array}$ & 9 \\
\hline Maranhão & 2 & Rio de Janeiro & 7 \\
\hline Mato Grosso & 2 & Santa Catarina & 3 \\
\hline
\end{tabular}

de Conclusão de Curso; e

6. novas áreas: Biologia Molecular, Genética Molecular, Farmacogenética, Avanços em Odontologia.

As dúvidas foram dirimidas com o suporte das ementas e dos programas dos respectivos cursos.

Para efeito de análise estatística, as cargas horárias das disciplinas foram somadas de acordo com a classificação acima. Foi utilizado o programa Statistica 5.0 e aplicado o teste de correlação de Pearson.

\section{RESULTADOS}

Foram analisados 89 currículos provenientes de todos os estados brasileiros que oferecem cursos de graduação em Odontologia, à exceção do estado do Tocantins, onde cursos foram implantados no ano de 2003. A amostra representa $52,35 \%$ dos 170 cursos de Odontologia do Brasil em 2003 (Edudatabase INEP/MEC).

Os dados referentes aos currículos, obtidos no banco de dados do INEP/MEC, foram diretamente fornecidos pelas próprias instituições por ocasião da avaliação institucional das condições de oferta do ano de 2002. Para resgatar os demais dados necessários à realização deste estudo, em seguida, foram procedidos contatos diretos com as instituições.

No caso das instituições estaduais e municipais, que não estão sujeitas à avaliação federal, os dados foram obtidos mediante solicitação direta ou nos sítios institucionais na Internet.

A amostra obtida está representada nas tabelas e gráficos apresentados. Na Tabela 2, pode ser observada a respectiva distribuição no que diz 


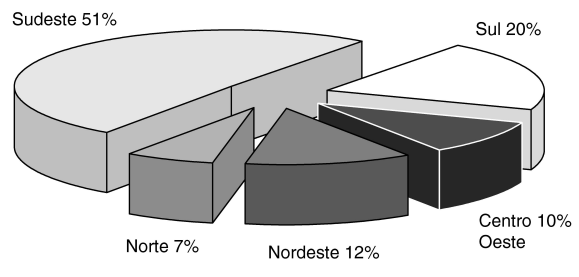

Gráfico 1 - Distribuição regional dos cursos.

respeito à dependência administrativa.

A representatividade dos estados da federação mostra a supremacia da região sudeste decorrente da concentração de cursos em São Paulo (Tabela 3).

No Gráfico 1 está a representação da distribuição regional que permite constatar que $50,6 \%$ dos cursos da amostra são oferecidos na região sudeste.

A distribuição do número de vagas é demonstrada no Gráfico 2.

A distribuição quanto ao regime pode ser verificada no Gráfico 3.

Os valores obtidos para média, em todos os quesitos avaliados, estão demonstrados na Tabela 4.

A média da carga horária total é de 4.730 horas, com a distribuição demonstrada no Gráfico 4.

A duração mínima dos cursos varia entre $4 \mathrm{e}$ 5 anos (Gráfico 5).

A média da carga horária básica é de 1.047 horas (Tabela 4), apresentando correlação positiva em relação à carga horária total (Gráfico 6).

A carga horária profissionalizante média é de 3.037 horas (Tabela 4) apresentando correlação positiva em relação à carga horária total (Gráfico 7).

Para a área de saúde coletiva, a carga horária média é de 257 horas (Tabela 4). Entretanto, a carga horária da área não apresenta correlação com a carga horária total (Gráfico 8).

A média da carga horária na área de Formação Científica é de 108 horas (Tabela 4), e não apresenta correlação com a carga horária total (Gráfico 9).

Na observação da área de Ética e Cidadania, a média verificada foi de 215 horas (Tabela 4) apresentando correlação positiva (Gráfico 10).

Em relação a novas áreas, a média é de 14 horas (Tabela 4 e Gráfico 11). Cabe ressaltar, entretanto, que 76 dos 89 cursos avaliados não contemplam a área. Não houve correlação com a carga horária total.

\section{DISCUSSÃo}

O modelo de ensino superior brasileiro, voltado para o mercado de trabalho, é centrado na formação técnica e dependente do conhecimento

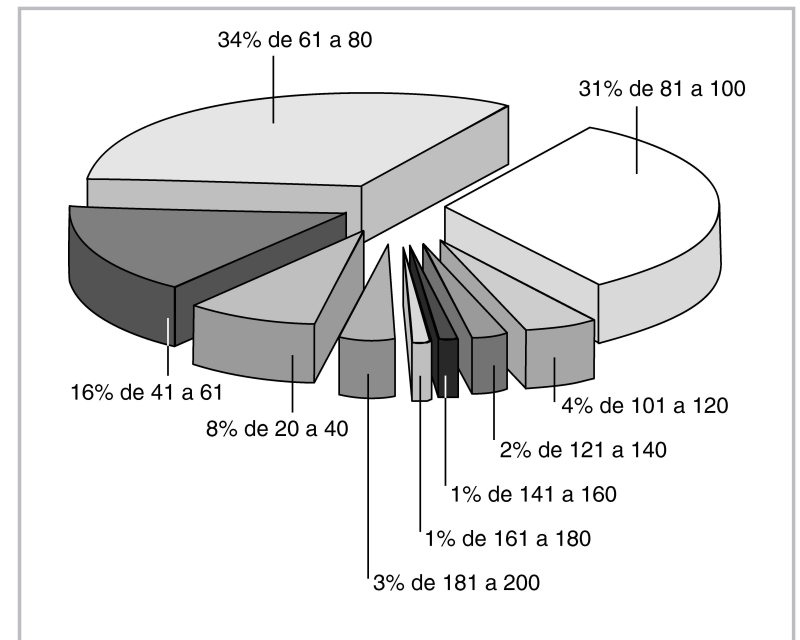

Gráfico 2 - Número de vagas.

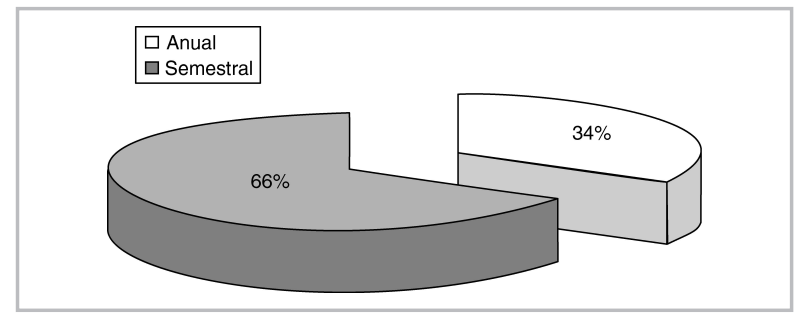

Gráfico 3 - Regime dos cursos.

externo, com dificuldades para criar e universalizar soluções adequadas à realidade social e tecnológica do país (MASETTO, 1998).

O ensino de Odontologia está adaptado a este contexto. É baseado na aplicação técnica, refletindo a marcante presença da indústria de equipamentos e materiais odontológicos. Observa-se na distribuição da carga horária profissionalizante a forte correlação entre a carga horária total e a parcela que é voltada para a formação profissionalizante (Gráfico 7$)$.

O conteúdo curricular é responsável pela formação de bases sólidas que propiciem pensamento crítico, fundamentado cientificamente. $\mathrm{Na}$ sua ausência provavelmente os profissionais terão dificuldades para fazer um julgamento criterioso do uso de novas tecnologias, diferenciando o que significa um avanço real do que é meramente um estratagema mercadológico. Tal comportamento é cada vez mais comum em razão da conjuntura decorrente do encontro de um mercado excessivamente competitivo com a realidade do setor: alto custo e população de baixa renda necessitando de atenção, número crescente de profissionais formados a cada ano (Tabela 1) e pequeno envolvimento do setor público na atenção à saúde bucal.

Por outro lado, os avanços biomédicos nas áreas 
Tabela 4 - Média e desvio-padrão dos quesitos avaliados.

\begin{tabular}{|l|c|c|c|c|c|}
\hline \multicolumn{1}{|c|}{ Carga horária } & Nos válidos & \multicolumn{1}{c|}{ Média } & \multicolumn{1}{c|}{ Mínimo } & \multicolumn{1}{c|}{ Máximo } & Desvio-padrão \\
\hline Total & 89 & $4.730,022$ & $3.390,000$ & $8.113,000$ & 703,7500 \\
\hline Básica & 89 & $1.046,775$ & 600,000 & $1.740,000$ & 213,2211 \\
\hline Profissionalizante & 89 & $3.036,652$ & $1.965,000$ & $5.966,000$ & 617,6573 \\
\hline Saúde Coletiva & 89 & 257,449 & 30,000 & 840,000 & 172,4106 \\
\hline Ética e Cidadania & 89 & 215,494 & 0,000 & 646,000 & 109,7386 \\
\hline Formação Científica & 89 & 107,978 & 0,000 & 400,000 & 75,3196 \\
\hline Novas áreas & 89 & 13,652 & 0,000 & 272,000 & 40,4416 \\
\hline
\end{tabular}

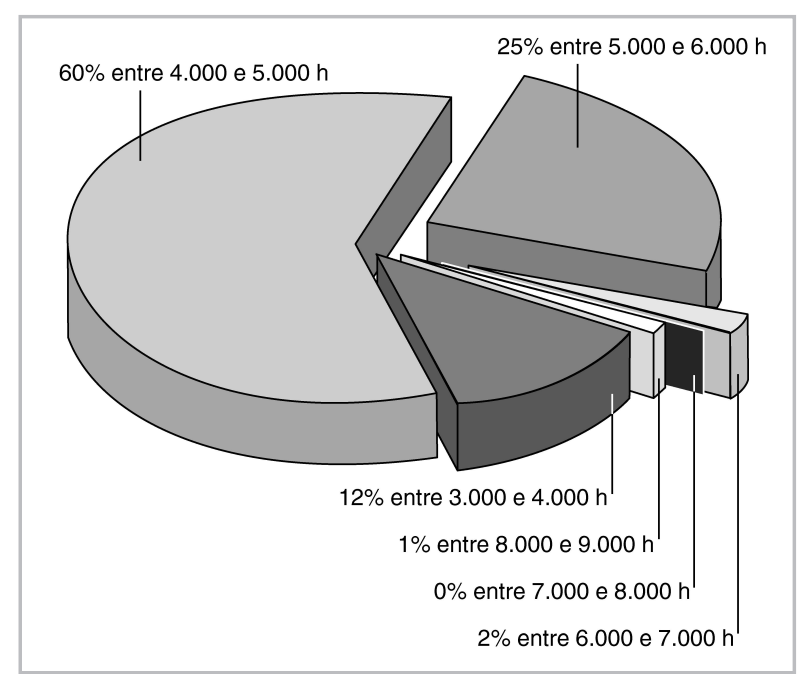

Gráfico 4 - Carga horária total dos cursos.

de diagnóstico propiciados a partir do mapeamento do genoma humano, provavelmente em um curto espaço de tempo, alterarão os critérios para definir doença e os métodos que hoje são empregados em diagnóstico e terapêutica (TEMPLE, 2001). Não se deve esquecer que o aluno de hoje é o profissional que estará no topo da sua carreira nos próximos 10-20 anos, oportunidade em os conhecimentos de que agora dispomos, provavelmente, estarão defasados e superados pelo avanço ininterrupto da ciência. (GUTTMACHER, Collins, 2002 e 2003). A atual velocidade do avanço dos conhecimentos é muito superior àquela verificada nos últimos 10 anos. A informática, a Internet e a bioinformática permitem a difusão e troca de conhecimentos de uma maneira nunca antes imaginada (Roos, 2001). A manutenção do status da profissão está incontestavelmente relacionada a sua capacidade de absorver conhecimentos e tecnologias que possibilitem a real melhoria da saúde bucal e, conseqüentemente, da qualidade de vida das pessoas (BAUM,

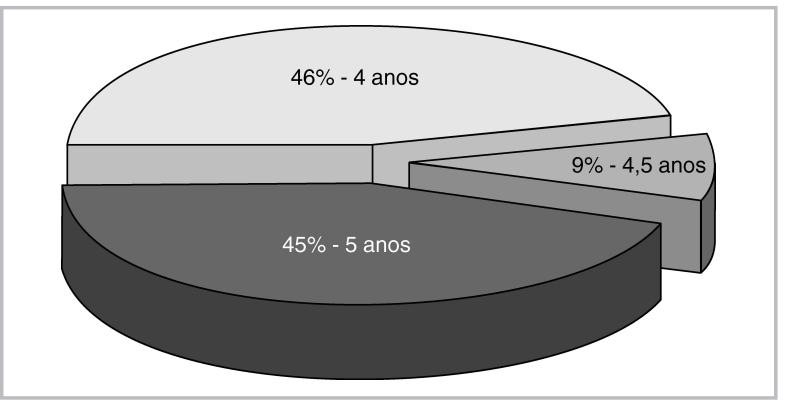

Gráfico 5 - Duração mínima dos cursos.

2003). Todavia, ao se verificar a atenção que os currículos dispensam a essas novas áreas do conhecimento constata-se a sua completa insipiência. A grande maioria ainda não destinou carga horária alguma às novas áreas, e a média de 14 horas é inadequada em números absolutos e em relação à carga horária total dos cursos (Gráfico 11).

É, cada vez mais, inadmissível desvincular saúde bucal da saúde geral. Dos profissionais da área serão cada vez mais exigidos conhecimentos sobre saúde geral, mecanismos de ação de novas drogas, novas terapias com interferências no padrão de saúde bucal.

Tendo em vista que as populações estão envelhecendo e que a prevalência de doenças crônico-degenerativas é maior em idades mais avançadas ocorre, também, um aumento da necessidade de conhecimentos básicos sobre os padrões de saúde e sobre tais doenças e suas interações com a cavidade bucal (SLAVKIn, 2001).

$\mathrm{Na}$ observação da área de formação científica, que capacita o aluno a entender $\mathrm{e}$ analisar publicações e inovações tecnológicas com visão crítica fundamentada cientificamente, verifica-se que a correspondente média de horas dispensada durante o curso é de 108 horas, com distribuição bastante heterogênea, entre 0 (zero) e 400 horas. 


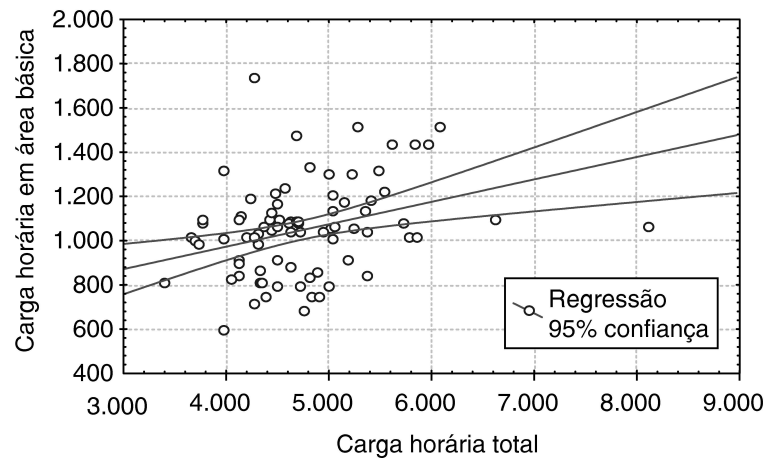

Gráfico 6 - Correlação entre a carga horária total e em área básica. Correlação (Pearson): $\mathrm{r}=0,33456$; $\mathrm{p}<0,05$.

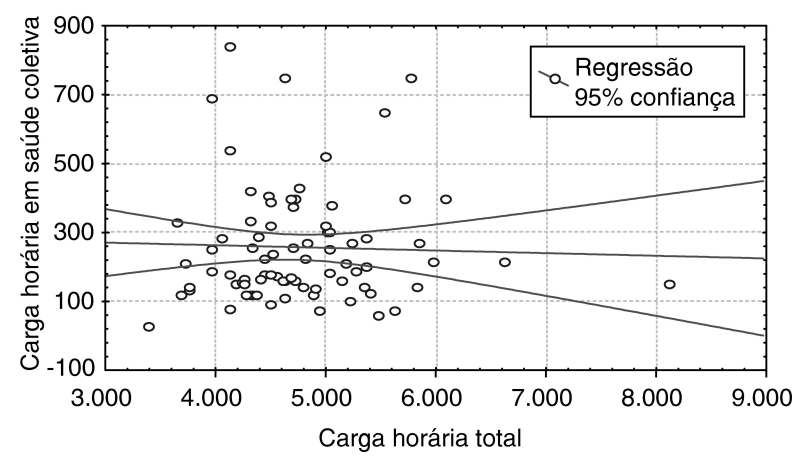

Gráfico 8 - Correlação entre a carga horária total e em saúde coletiva. Correlação (Pearson): $r=-0,0312 ; \mathrm{p}>0,05$.

Considerando que não existe correlação, fica demonstrado que cursos que apresentam maior carga horária não oferecem, necessária e proporcionalmente o mesmo número de horas destinadas à formação científica (Gráfico 9).

A análise do número de horas destinado à área básica do curso revela que a maioria oferece carga horária entre 1.000 e 1.100 horas, sendo a média de 1.047 , portanto, uma distribuição irregular. São encontrados cursos com carga horária de aproximadamente 600 horas, outros acima de 1.300 atingindo o limite de 1.740 , com baixa correlação entre a carga horária total e a básica (Gráfico 6).

Ao profissional do futuro deverá ser oferecida fundamentação nos conhecimentos básicos muito superior àquela que hoje lhe é destinada, vez que lhe será exigido muito mais face aos avanços dos conhecimentos na área das ciências da saúde. Não bastará, então, dispor de noções básicas de Anatomia, Histologia, Fisiologia, Microbiologia, Imunologia, Patologia, Genética e Farmacologia, entre outras. Far-se-á necessário o conhecimento profundo que sustente a interação e aplicação das novas tecnologias que hoje despontam como o caminho das ciências da saúde (NASH, 1995). Na

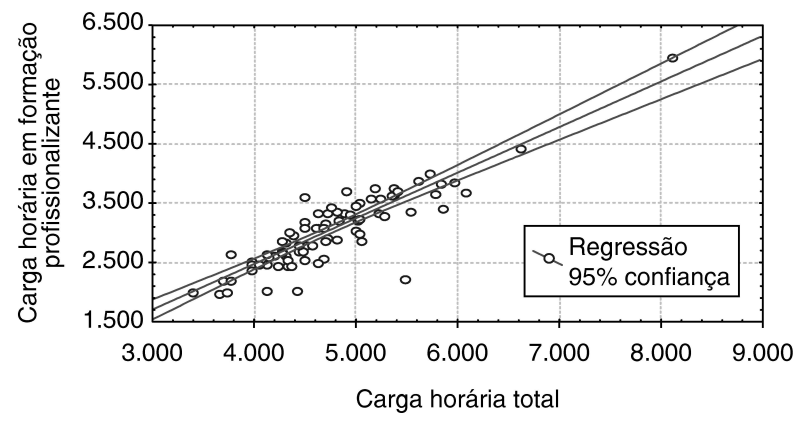

Gráfico 7 - Correlação entre a carga horária total e em formação profissionalizante. Correlação (Pearson): $\mathrm{r}=0,87653 ; \mathrm{p}<0,05$.

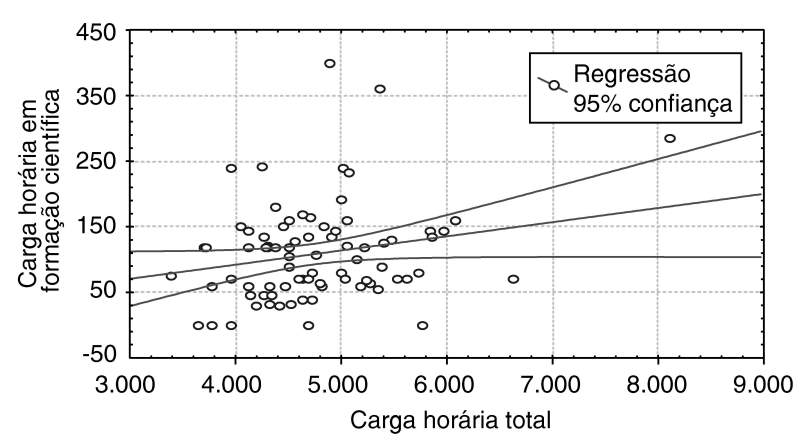

Gráfico 9 - Correlação entre a carga horária total e em formação científica. Correlação (Pearson): $r=0,20178$; $\mathrm{p}>0,05$.

hipótese de não se proceder à devida correção no eixo de formação dos graduandos em Odontologia, apresenta-se o risco de perpetuar a carreira sob a égide de uma formação prioritariamente técnica (NASH, 1996 e 1998; BAUM, 1997) e sem a necessária expressão no âmbito das profissões da saúde.

$\mathrm{Na}$ área de ética e cidadania verifica-se carga horária média de 215 horas com uma reduzida correlação em relação à carga horária total. Por outro lado, podem ser observados casos em que a área não é parte do currículo, enquanto outros apresentam mais de 600 horas, o que demonstra a heterogeneidade da distribuição (Gráfico 10).

$\mathrm{Na}$ análise da carga horária da área de saúde coletiva e carga horária total, em que não há correlação, fica constatado que a maioria dos cursos ainda não a incorporou em seus currículos de maneira efetiva, o que denota o descaso com o papel e a real importância da saúde pública (Gráfico 8). É óbvio que uma profissão se faz reconhecida moral e eticamente na mesma medida em que beneficia o conjunto da sociedade e, não apenas, parcelas privilegiadas no contexto do país, que dispõem de recursos financeiros para custeá-la.

É preciso coragem e disposição para romper o 


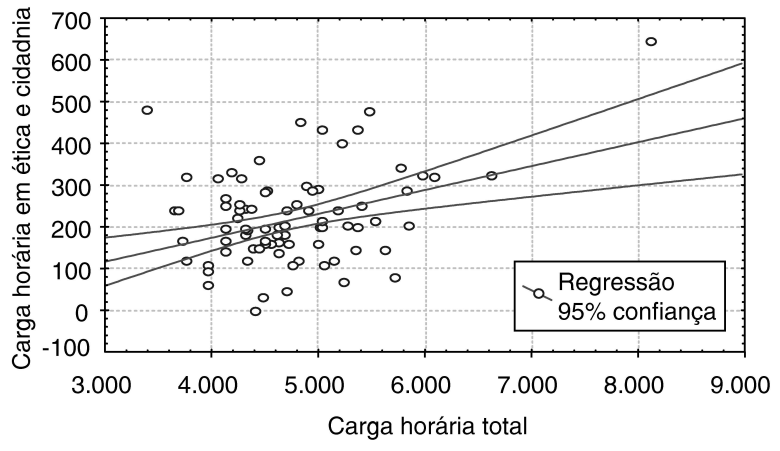

Gráfico 10 - Correlação entre a carga horária total e em Ética e Cidadania. Correlação (Pearson): $r=0,36745$; $\mathrm{p}<0,05$.

imobilismo que, de modo geral, rege a formação odontológica. Em uma primeira fase são ofertadas noções básicas das ciências da saúde, e em um segundo momento, grande carga e ênfase são reservadas à formação técnica profissional. Os currículos em geral são pautados pela divisão das disciplinas, tratadas como se fossem especialidades inseridas na formação de graduação (CHAMBOULEYRON, 2001). Ao alunado é exigido que reúna as partes na tentativa de alcançar e entender o todo. Verifica-se que, no final, resulta na construção de uma clínica de aplicação prática do conjunto de conhecimentos, mesmo no que diz respeito àqueles currículos que julgam integrar a formação. Na realidade os conhecimentos permanecem fragmentados. A simples aplicação em conjunto não resulta em integração. Esta é uma das questões cruciais a ser superada na aplicação dos conceitos de interdisciplinaridade e transdisciplinaridade (ROBLES, 1998), recomendados pelas Diretrizes Curriculares. Talvez a introdução de metodologias como o ensino de Odontologia baseado em evidências facilite esta integração (DODSON, 1997).

Tais dificuldades decorrem, evidentemente, também da inadequada formação do professor. A observação da história dos cursos de Odontologia no Brasil denota que, no início, os professores eram aqueles que obtinham sucesso profissional externo à docência (CARvalho, 2001). Ainda hoje este modelo é observado em parte do corpo docente. É bem verdade que os modelos de avaliação do INEP/MEC e da Coordenação de Aperfeiçoamento de Pessoal de Nível Superior (CAPES) aplicados nos últimos anos têm conseguido modificar esse perfil e, atualmente, o número de docentes mestres e doutores tem apresentado um considerável aumento (Censo da Educação Superior 2002 INEP/MEC).

O alunado, por sua vez, ao espelhar-se no sucesso profissional do professor cultiva a idéia de que o

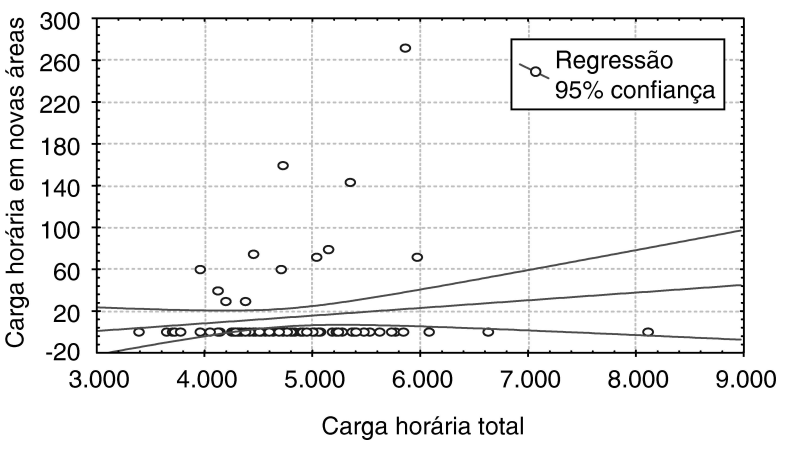

Gráfico 11 - Correlação entre a carga horária total e em novas áreas. Correlação (Pearson): $r=0,12802 ; \mathrm{p}<0,05$.

melhor professor é o que executa bem uma tarefa técnica. É grande a dificuldade de perceber que o professor ideal é aquele que lhe permite adquirir ferramentas indispensáveis a um futuro crescimento. O domínio de técnicas é, exclusivamente, uma questão de tempo aliado à perseverança e ao treinamento. Todos o alcançarão. Alguns com mais, outros com menos tempo e facilidade.

A era da Odontologia como arte, obra de artesão, está ficando no passado. Profissionais com habilidades técnicas são necessários e o serão sempre. Contudo o novo profissional que se avizinha há que apresentar iguais competências científicas em conhecimento básico das ciências da saúde, dos problemas de saúde populacionais e dos caminhos a serem trilhados no futuro próximo.

É premente a completa integração entre ciência básica e ciência odontológica, entre o básico e o profissionalizante e entre o individual e o coletivo visando soluções novas para problemas antigos que continuam a se perpetuar.

Cabe, ainda, ressaltar que as observações realizadas dizem respeito unicamente ao percentual de tempo dedicado a cada área analisada. Portanto exclua-se intenção de julgar a qualidade do ensino. Por outro lado, é indiscutível que a importância dada à determinada área está refletida na correspondente carga horária.

Dessa forma, e tendo em vista as Diretrizes Curriculares recém-implementadas, há que se ressaltar a urgente necessidade de implantação das decorrentes mudanças na grande maioria dos cursos.

\section{CONClusões}

Foi observado que os currículos expressam uma gama de variações na composição das respectivas cargas horárias. No entanto, são pontos pacíficos o 
proeminente tratamento dado à formação técnica e a separação entre as áreas de formação básica e profissionalizante nos currículos formalmente estruturados.

$\mathrm{O}$ tratamento dispensado às áreas de formação em Saúde Coletiva e em Ética e Cidadania é bastante díspar, dependente do perfil que cada curso pretenda dar ao seu alunado.

A introdução de novas áreas do conhecimento é incipiente, o que denota a ausência de atenção destinada ao tema por parte da administração dos cursos.

Fica patente a necessidade de reorientação para a correspondente adequação dos cursos às novas Diretrizes Curriculares.

\section{ABSTRACT}

\section{The structure of curricula in Brazilian dental} education

Formal dental education in Brazil began in the last three decades of the $19^{\text {th }}$ century and has significantly progressed through the years. Nevertheless, the main focus of curricula has been centered on technical education. Based on the curricula database of the National Institute of Educational Research, Ministry of Education and Culture (INEP/MEC), this study evaluated the undergraduate curricula of Brazilian dental schools by assessing the proportion of hours dedicated to basic education, professional education, ethics and citizenship, public health and new areas in relation to the total hours of the courses. In this way, it is possible to observe the importance given to each area in the general organization of dentistry courses in Brazil.

\section{DESCRIPTORS}

Teaching. Education, dental. Curriculum.

\section{REFERÊNCIAS BIBLIOGRÁFICAS}

BAUM, B. J. The absence of a culture of science in dental education. EurJDent Educ, v. 1, n. 1, p. 2-5, Feb. 1997.

BAUM, B. J. et al. Global challenges in research and strategic planning. EurJ Dent Educ, v. 6, Suppl. 3, p. 179-184, 2002.

BAUM, B. J. Can biomedical science be made relevant in dental education? A North American perspective. EurJDent Educ, v. 7 , n. 2, p. 49-55, May 2003.

BERTOLAMI, C. N. Rationalizing the dental curriculum in light of current disease prevalence and patient demand for treatment: form vs. content. JDent Educ, v. 65, n. 8, p. 725-735; discussion 736-743, Aug. 2001.

CARVALHO, A. C. P. Ensino de Odontologia em tempos da LDB. 1. ed. Canoas : ULBRA, 2001

CHAMBOULEYRON, I. Mais vagas com qualidade o desafio do ensino superior no Brasil. 1. ed. Campinas : UNICAMP, 2001.

CONSELHO NACIONAL DE EDUCAÇÃO. Diretrizes Curriculares Nacionais do curso de graduação em Odontologia. Resolução CNE/CES 3/2002, Diário Oficial da União, Brasília, 4 de março de 2002, Seção 1, p. 10.

DODSON, T. B. Evidence-based medicine: its roles in the modern practice and teaching of dentistry. Oral Surg Oral Med Oral Pathol Oral Radiol Endod, v. 83, n. 2, p. 192-197, Feb. 1997.

FERNANDES NETO, A. J. A evolução dos cursos de Odontologia no Brasil. Revista da ABENO, v. 2, n. 1, p. 55-56, 2002.

GUTTMACHER, A. E.; COLLINS, F. S. Genomic medicine - a primer. NEngl J Med, v. 34, n. 7, p. 1512-1520, 2002.

GUTTMACHER, A. E.; COLLINS, F. S. Welcome to the genomic era. N Engl J Med, v. 349, p. 996-998, Sept. 2003.

HART, T. C.; MARAZITA, M. L.; WRIGHT, J. T. The impact of molecular genetics on oral health paradigms. Crit Rev Oral Biol Med, v. 11, n. 1, p. 26-56, 2000.

INEP/MEC. Censo da Educação Superior 2002. Disponível em: http://www.inep.gov.br/. Acesso em: 24/10/2003.

INEP/MEC. Edudatabase: acompanhe a evolução dos indicadores educacionais do Brasil. Cursos de graduação. Disponível em: http://www.inep.gov.br. Acesso em: 24/10/2003.

MASETTO, M. T. Discutindo o processo ensino-aprendizagem no ensino superior. In: MARCONDES, E.; GONÇALVES, E. L. Educação Médica. 1. ed. São Paulo : Sarvier, 1998. p. 11-19.

MASETTO, M. T. The oral physician... creating a new oral health professional for a new century. J Dent Educ, v. 59, n. 5, p. 587-597, 1995.

MASETTO, M. T. The cultural wars are not imaginary. JDent Educ, v. 60, n. 11, p. 891-894, 1996.

NASH, D. A. "And the band play on...". J Dent Educ, v. 62, n. 12, p. 964-974, 1998.

ROBLES, H. J. Interdisciplinary courses and programs: pedagogy and practice. Recommendations for planning, implementation, and evaluation. California : Community Colleges, 1998. 145 p.

ROOS, D. S. Computational biology. Bioinformatics-trying to swim in a sea of data. Science, v. 291, n. 5507, p. 1260-1261, Feb. 2001.

SLAVKIN, H. C. And the next 50 years? The future of recombinant DNA tecnology in oral medicine. JPublic Health Dent, v. 56, n. 5 , Special Issue, p. 278-285, 1996.

SLAVKIN, H. C. Thoughts on the future of dental and craniofacial research. Compendium, v. 21, n. 10A, p. 927-930, Oct. 2000.

SLAVKIN, H. C. The human genome, implications for oral health and diseases, and dental education. J Dent Educ, v. 65, n. 5, p. 463-479, May 2001.

TEMPLE, L. K.; MCLEOD, R. S.; GALLINGER, S.; WRIGHT, J. G. Defining disease in the genomics era. Science, v. 29, n. 3, p. 807-808, Aug. 2001.

YEAGER, A. L. Where will the genome lead us? Dentistry in the $21^{\text {st }}$ century. JAm Dent Assoc, v. 132, p. 801-807, Jun. 2001.

Aceito para publicação em 11/2003 